\title{
Energy savings in transportation: Setting up an innovative SHM method
}

\author{
R. Fedele*, F. G. Praticò, R. Carotenuto, F. G. Della Corte \\ University "Mediterranea” of Reggio Calabria, Via Graziella, 89124 Feo di Vito, Reggio Calabria (RC), Italy \\ Corresponding Author Email: rosario.fedele@unirc.it
}

https://doi.org/10.18280/mmep.050408

Received: 17 June 2018

Accepted: 13 November 2018

\section{Keywords:}

energy savings, management process improvement, $P-F$ curves, road pavement, structural health monitoring

\begin{abstract}
Transportation systems are gradually changing. Innovative solutions are provided by automotive industries, construction firms, computer-aided pavement management systems, sensor-based structural health monitoring (SHM) systems, and international regulations. This calls for efforts and studies aiming at finding a trade-off between the ever-growing request of innovation (smart cities), and the never-ending depletion of resources and energy. Energy savings in road infrastructures can be pursued through: 1) construction process optimization; 2) traffic management improvement; 3) vehicle optimization; 4) recycling and reuse of construction materials; 5) innovative materials; 6) energy harvesting; 7) smart roads; 8) maintenance and rehabilitation optimization through SHM methods and technologies. The objective of the study is to set up an innovative SHM method aiming at achieving energy savings in transportation in terms of Pavement Management System (PMS) optimization. The new method here setup was implemented through an experimental investigation. A microphone was placed on different road pavements, impulse loads were produced by a Light weight Deflectometer, LWD, and vibro-acoustic signals were recorded and analyzed in the pursuit of assessing the structural condition of the pavement. Using this knowledge to improve the management process of transportation infrastructures, it is expected that safer, more resilient, and less energy-consuming assets will be provided.
\end{abstract}

\section{INTRODUCTION}

The field of the transportation is gradually changing because of the new solutions offered by: i) automotive industries; ii) construction enterprises; iii) Internet of Things (IoT); iv) sensor-based structural health monitoring (SHM) systems; v) international regulations.

These continuous upgrading call for a careful analysis of the current situation and a proper tuning of the design and management of the transportation infrastructures. It should aim at finding a trade-off between the ever-growing request of innovation (smart cities), and the never-ending depletion of the available resources.

This section of the paper illustrates several relevant examples of possible solutions that may be implemented on road infrastructures to reduce the actual need of resources (in terms of energy, materials, money, time, and workers). Section 2 focuses on motivations and objectives, while the successive sections deal with the method set up, results obtained, and conclusions.

\subsection{Construction process optimization}

Recent studies show that it is possible to optimize the road construction process acting on three important stages of the Hot Mix Asphalt (HMA) production, i.e., aggregates drying, and bitumen/bituminous mixture heating [1]. In particular, by using natural gas as fuel, energy savings (more than $60 \mathrm{MJ}$ ), carbon emission reduction (more than 30\%), and costs reduction (more than 35\%) can be achieved.
Warm and Cool Mix Asphalt were proposed as an alternative to HMA. They allow saving energy and reduce greenhouse gas (GHG) emissions (i.e., carbon footprint) because of lower temperatures, using alternative binders (e.g., emulsified bitumen or cement) and new technologies [2-3]. Even though WMAs often show a good performance over time in terms of fatigue resistance (durability), their design must be improved in terms of rutting behavior [2].

\subsection{Traffic management improvement}

Traffic management is often considered as a key solution to tackle congestion, to reduce travel times, to improve flows, to reduce emissions (and save energy), and to exploit the effective road capacity [4]. Nevertheless, if stochastic uncertainty and fluctuations related to the traffic flow (connected to human driving behavior) are not carefully considered on a case-by-case basis, the effectiveness of this solution may be reduced. Real time traffic management systems have been proposed in order to intelligently pilot the vehicles, discourage the formation of gridlock, and optimize power requirement of hybrid vehicles (e.g., fuel cell-based, or autonomous) [5-6].

\subsection{Vehicle optimization}

Different approaches have been adopted by the automotive industry to design more sustainable and less consuming vehicles, for example, 1) based on fuel type and/or quality; 2) based on engines technology; 3) having lighter and 
aerodynamic vehicles; 4) using automated vehicles or selfdriving cars [7-9].

Electric vehicles will likely represent the future of the automobile industry because they seem to be environmentally friendly (zero GHG emission), to reduce operational costs compared to traditional vehicles (an electric vehicle costs 10 cents per mile less than a petrol powered vehicle; cf. [7]). They need $1 \mathrm{KWh}$ to travel for 4-8 miles and they have an energy efficiency of around $75 \%$ while the traditional ones use only the $15 \%$ of the total fuel energy [7]. Nonetheless, there are still problems related to their overall high costs (due for $1 / 3$ to the cost of the electricity used to power the car; cf. [7]), to their powertrain (type, size, charging protocol, battery size, timing, etc.), to the energy management approach used (i.e., battery size, or the vehicle velocity), and to the driving cycles (i.e., how the driver doses the speed), and to the current infrastructure performance (to service and maintain electric cars) [6-7][10-11]. Electric car powered by fuel cells fed with hydrogen from clean renewable sources (e.g., wind or solar) represent a promising solution for the current problems related to the electric cars mentioned above [7]. Actually, their development and diffusion depend on high costs, low durability and hydrogen storage problems (i.e., refueling infrastructure-related). Automated vehicles were proposed to optimize fuel consumption, but recent studies demonstrate that they lead to poor results in terms of energy use and GHG emissions [9], and that they will probably arrive too late to make an impact. Besides these drawbacks, there are also problems related to: i) the safety of passengers, pedestrians and cyclists; ii) cyber security (e.g., terrorism, or malicious hacking); iii) their dimensions because now they are perceived as mobile offices or entertainment centers; iv) marketability.

\subsection{Recycling and reuse of construction materials}

The most common way to recycle road pavement materials is to reuse Reclaimed Asphalt Pavement (RAP). In a recent study [12], to quantify energy consumption and GHG emissions of asphalt pavement containing RAP, a thorough analysis about raw materials acquisition, plant production, construction, maintenance, and pavement end-of-life was carried out. The authors concluded that the energy consumption strictly depends on RAP and moisture contents, blending efficiency, and performance levels. This study underlines the fact that this is an efficient and well-established solution to reduce consumption in transportation, but a proper design is needed in order to avoid a subsequent increase of the maintenance activities that lead to an increase of GHG emission and energy consumption.

\subsection{Innovative materials}

In the last years, studies have been carried out aiming at using waste materials as construction materials. Road construction alternative materials have been proposed and analyzed in terms of Lifecycle Cost Analysis (LCA; [13]. Byproducts (e.g., crumb rubber, plastics, blast furnace slag, fly ash, leachate, glass, concrete, wood ash) have been recently taken into account as alternative materials because of the restrictions on landfill disposal [14-18]. The effects of including these materials might have positive or negative consequences on road pavements and their lifetime, but there are unquestionable positive effects in terms of raw material needs/processing and carbon footprints. The success related to this solution is greatly influenced by the technical readiness level, the obstacles from legislation, the involvement of several stakeholders (e.g., the waste management professional, or the scientific community) [17]. The improvement in oil refinery technology has had negative effects on bitumen-based binder quality [19-20]. For this reason, studies are investigating the possibility of creating and using bio-oil byproducts (e.g., waste cooking oil) as a substitute to bitumen (bio-binders). Bio-binders may have higher recovery ability and fatigue performance than conventional petroleum-based binders, but this success strictly depends on their inner characteristics, which influence the heating and mixing processes [19-20].

\subsection{Energy harvesting}

Energy harvesting can be pursued considering different phenomena related to the road pavement and the traffic. Piezoelectric-based devices, for example, gather energy from the vibrations generated by the vehicles (see e.g., [21-22]). Through these devices, embedded into the road pavement, it is possible to produce energy to power traffic facilities (e.g., street lights and signs), avoiding long-distance electricity facilities, and getting real-time traffic information (e.g., loads and speeds). On the other hand, (i) road performance could be affected; (ii) devices hardly controllable efficiency (vibrationrelated problems) is a recurring issue; (iii) their duty cycles should be accorded to the traffic; (iv) they should be designed according to pavement stresses, strains, and vibrations; and (v) the durability of these devices is a big issue. Solar roads are emerging as one of the energy source of the future. They include photovoltaic (see e.g., [23]), and hydronic technologies (see e.g., [24]). They have the potentiality to produce electricity, and store heat concurrently, but they must guarantee performances (e.g., roughness, stiffness, sustainability) that must be comparable with those of traditional (asphalt-based) roads. Several solutions have been presented to optimize this type of roads, from both energy [25] and structural/security [23] point of view. Hydronic asphalt pavements (HAPs) have been proposed for energy harvesting and snow melting [24]. Fluids circulating in a network of embedded pipes allow capturing and storing solar energy (as heat). Unsolved problems related to this technology refer to construction (needs of reinforced grid) and maintenance, and long-term performance evaluation.

\subsection{Smart roads}

Future cities must be able to improve the daily life of their citizens and, to achieve this goal, in the last years, the concepts of Intelligent Transportation System (ITS; cf. [26]) and "smart city" emerged. These ideas have all the potentialities to succeed because they combine the world of Internet of Things (IoT) with the Information and Communication Technologies (ICTs). Despite its potential, this approach is very complex because it involves several sectors, stakeholders, authorities, services, and its implementation must take into account: i) innovative ways to share the information (e.g., mobile applications); ii) alternative transportation modes (e.g., bike or car sharing); iii) sustainable strategies (e.g., free electric charging stations for electric vehicles); iv) intelligent traffic lights systems or parking; v) adopting innovative and efficient Pavement Management Systems (PMSs). Smart street lighting entails traffic safety, visual comfort, and energy-savings at the 
same time [27-29]. It is important to note that, even if street lighting is governed by a huge number of parameters, new technologies (e.g., LED luminaries, or simulation software; cf. [29]) can ensure good performance and high energy/economic savings. On the other hand, this solution introduces nondisruptive innovations to solve the problem of the energy consumption in transportation.

\subsection{Maintenance and rehabilitation optimization through SHM methods and technologies}

The preservation of the infrastructure assets is commonly accomplished through the Pavement Management System (PMS) approach, which is likely the most widespread and cost-effective tool used by officials and practitioners [30]. PMS is used to gather information from the asset, to identify backlog work, to set goals, and schedule (e.g., for 3-5 years) maintenance and rehabilitation in order to prioritize and limit the interventions, and saving time, energy, and money (as budget stretching and return on investment). Usually, the approach "worst-first" is considered as the best way to fix a pavement, but using a PMS is possible to clearly see that is less expensive to maintain pavement in decent condition than completely reconstruct it, when it is in bad conditions (e.g., reconstruct 1 mile of road corresponds to preserve or treat 8 miles; cf. [30]). In order to give an idea of the advantages provided by the adoption of a PMS, Figure 1 and Table 1 are here included. One of the main results of the PMS is the estimation of road pavement condition variation over time (Figure 1). Commonly, pavement conditions are expressed through deterioration curves, which show the variation over time of indices such as the Present Serviceability Index (PSI), the Present Serviceability Rating (PSR), the Mean Panel Rating (MPR), the Pavement Condition Index (PCI), the Pavement Condition Rating (PCR), the Ride Number (RN), the Profile Index (PI), and the International Roughness Index (IRI) [30-31]. Pavement deterioration can be studied in terms of machine fault monitoring, i.e., in terms of P-F interval and its graphical representation in a plot of time (x-axis) versus functional capability (y-axis; cf. [32]). This time interval indicates the exposure to stress between the instant, $\mathrm{P}$, at which a potential failure (detectable symptom, warning sign, potential failure symptom) can be detected and the time, F, when the functional failure occurs. Different factors are taken into account to estimate a pavement condition. For example, material type, age, geometry, drainage, substructure conditions and construction history, basic geophysical segmentation, average daily traffic, functional class, and thickness (Cf. [30]) are the factors used to derive the PCI. In order to assess a road pavement performance (e.g., practicability, availability, and safety, during normal and emergency situations), monitoring is needed and a number of strategies, based on several SHM methods and devices, can be applied (see e.g. [22, 40-43]). The information gathered during the monitoring can be used as decision support by the authorities (public or private) deputed to the construction and maintenance of the road infrastructures to improve the management process, or by the users to optimize their trips in terms of travel time, costs, safety, and consumptions.

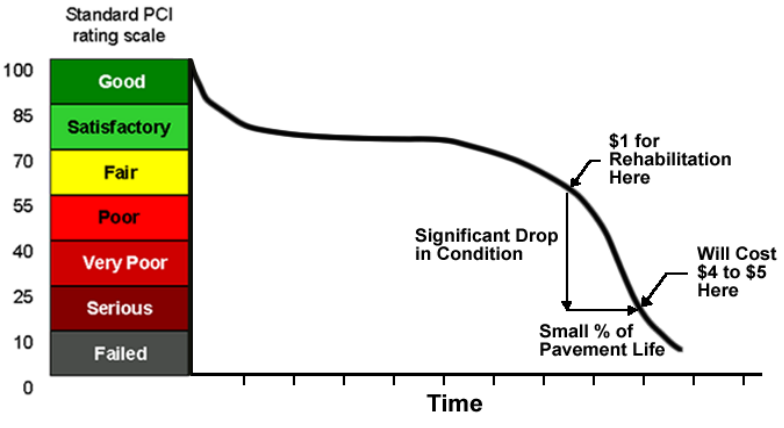

Figure 1. Example of deterioration curve [33]

Table 1. PMS's economic advantages

\begin{tabular}{|c|c|c|}
\hline Pavement condition & Cost $/$ sy $^{1}$ & Reference \\
\hline $\mathrm{PCI}=60 \%$ & $1 \$$ & [30] \\
\hline $\mathrm{PCI}=20 \%$ & $8-10 \$$ & \\
\hline 40\%Road Lifetime (PCI $\approx 100-80 \%$ ) & $0.85 \$$ & [34] \\
\hline 70\%Road Lifetime (PCI $\approx 80-60 \%)$ & $4.25 \$$ & \\
\hline 90\%Road Lifetime (PCI $\approx 60-20 \%$ ) & $7.50 \$$ & \\
\hline $100 \%$ Road Lifetime (PCI $\approx 20-0 \%$ ) & $16.75 \$$ & \\
\hline Good $(\mathrm{PCI} \approx 80 \%)$ & $7-9 \$$ & [35] \\
\hline Poor/Fair (PCI $\approx 50 \%)$ & $15-20 \$$ & \\
\hline Very Poor $(\mathrm{PCI}<20 \%)^{2}$ & $50-55 \$$ & \\
\hline $\mathrm{PCI} \approx 90 \%$ & $1 \$$ & [36] \\
\hline $\mathrm{PCI} \approx 30 \%$ & $6-10 \$$ & \\
\hline 75\%Road Lifetime (PCI $\approx 60 \%$ ) & $1 \$$ & {$[37]$} \\
\hline $83 \%$ Road Lifetime (PCI $\approx 20 \%$ ) & $4-5 \$$ & \\
\hline 75\%Road Lifetime (PCI $\approx 60 \%$ ) & $1 \$$ & [38] \\
\hline $88 \%$ Road Lifetime ( $\mathrm{PCI} \approx 20 \%$ ) & $6-14 \$$ & \\
\hline Good-Excellent (PCI $\approx 90 \%)$ & $1-2 \$$ & [39] \\
\hline Good $(\mathrm{PCI} \approx 80 \%)$ & $6-9 \$$ & \\
\hline Fair (PCI $\approx 60 \%)$ & $10-14 \$$ & \\
\hline Very Poor $(\mathrm{PCI}<20 \%)^{2}$ & $60 \$$ & \\
\hline
\end{tabular}

Notes: 1. Cost of preventive maintenance per Square yard; 2. Costs referred to the road pavement reconstruction. 1 square yard $=0.836127$ square meter.

Infrastructure monitoring can be carried out using traditional destructive testing (DT) or innovative nondestructive testing (NDT, see e.g., [44]). Usually, DT is the most used because of the fact that (i) it is based on wellestablished and accurate methods, (ii) it derives the characteristics of the road pavement from samples of the pavement (e.g., after coring), (iii) technology requirements and worker's knowledge and skills (e.g., to carry out the measurements, or to process the data) are usually already in place. Despite the above-mentioned strengths, beside the fact of providing sample-based information (i.e., discrete points of the pavement), DT requires energy and money for extracting (e.g., coring), analyzing, and landfilling pavement samples. On the other hand, NDT-based methods, driven by the increasingly insistent demand for smart cities, are growing in relevance versus traditional DT methods, offering high performance (e.g., extended measurements), sustainability (e.g., energy and time savings), and efficiency (e.g., high measurement frequency, and/or technologically advanced devices). The main NDT drawbacks are related to the costs (i.e., instrumented infrastructures are more expensive than traditional ones), and to the worker's skill (i.e., skilled worker are required to set up, use, and tune sophisticated 
devices/systems, and/or to handle and analyze huge amounts of data). From an energy point of view, it should be underlined that the NDT methods tend to be more sustainable than the DT methods, because they use efficient and advanced systems (e.g., network of wireless sensors [45], cloud-based data management systems [46], low-power consumption/selfpowered sensors [22].

\section{MOTIVATIONS AND OBJECTIVES}

The motivations behind the study presented in this paper refer to maintenance and rehabilitation optimization through SHM methods and technologies. As described in the previous section, this process is usually based on PMSs. In paragraph 1.8 , the main characteristics of the PMSs were introduced and discussed. As mentioned above, during the application of the PMS, to properly estimate pavement conditions and to build efficient and useful deterioration curves, different parameters (e.g., material type, age, structural health status, stiffness) should be taken into account. These parameters are often derived through methods that have several defects mainly related to safety, comfort, environment pollution, and management (e.g., need to limit/interrupt the traffic flow; and/or need skilled practitioners to carry out the measurements and to extracts these factors from the gathered data; and/or are energy consuming; and/or are based on destructive tests; and/or have an unsustainable carbon footprint).

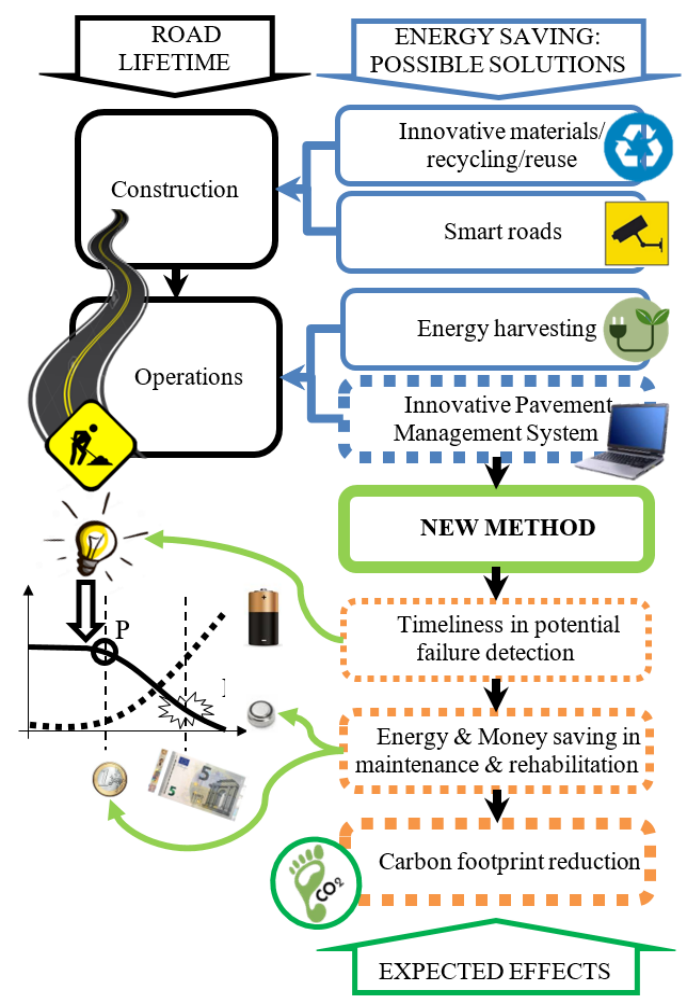

Figure 2. Summary of the study

Consequently, the objective of this study is presenting a method that aims at: 1) limiting the drawbacks related to PMS input parameter commonly used; 2) introducing innovative PMS input factors; 3) promptly detecting potential failure symptoms (first point of the P-F interval) and consequently saving energy and other important resources (e.g., time, money, construction material, etc.) through the improvement of the actual PMSs.

Figure 2 summarizes the study showing: i) road pavement lifetime as the combination of the construction and operations; ii) the possible solutions to save energy during the road lifetime as in section 1; iii) the solution "Innovative Pavement Management System", herein focused; iv) the new proposed method and its effects in the short (i.e., timeliness in potential failure detection), middle (i.e., energy and money saving in management due to the PMS optimization) and long term (i.e., carbon footprint reduction). Furthermore, it contains a conceptual illustration of: i) a typical road deterioration curve and its P-F interval (solid line, where $\mathrm{P}$ represents the potential failure, $F$ stands for Functional Failure); ii) a typical management cost curve (dotted line); iii) energy and money savings as a function of symptom detection $(\mathrm{P})$ and of the consequent maintenance scheduling.

\section{METHOD: DEFINITION AND VALIDATION}

This section aims at describing the method here proposed as a possible solution to improve PMSs used for the management of road infrastructures, and at presenting the experimental investigation that was carried out for its validation.

\subsection{The method}

The core idea behind the proposed method and this study is to replace/ improve the traditional parameters used as input into PMSs, through innovative input parameters (features) derived from signals, hopefully through efficient, low-power, and non-destructive technologies. In order to achieve the previous objectives, a new method was designed and a new system was set up that has the following characteristics: a) it is based on non-destructive low-power electronic system (i.e., sensors placed on the road pavement); b) it does not interfere with traffic (i.e., sensors are outside the carriageway); c) it does not need skilled workers, i.e. it is able to automatically extract the required information from the signals gathered through the sensors; d) instead of traditional PMS input parameters, it uses the information (features), extracted from the acoustic signatures of the road pavement; e) it allows detecting, in real time and with a high sampling frequency, potential failures that occur in pavement layers. This ability leads to improve the actual PMS and to save resources (cf. section 4).

\subsection{Experimental investigation: Method validation}

A SHM method, presented in a previous study of the same authors of this paper [47], was applied to carry out an experimental investigation that aimed at validating the proposed method. A non-destructive microphone-based electronic system was used to gather the acoustic responses of cracked (i.e., superficially and internally damaged, herein called $\mathrm{C}$ section), and un-cracked (herein called UC section) pavements to impulse loads generated using a Light Weight Deflectometer (LWD, model PRIMA 100, Grontmij; Figure 3). As is well known, the LWD is a device typically used to assess the elastic modulus ( $E$, also called dynamic modulus) of the layers of a pavement according to the standard ASTM E258307 [48]. In this case, it was used for two important reasons: 1) as a mechanical source of vibrations able to generate acoustic signals that can be detected and recorded through the SHM 
system; 2) to measure the elastic modulus $(E)$ of the pavement. The microphone, M (Cf. Figure 3), of the SHM system was located on the pavement and the LWD was moved along a line orthogonally to the traffic direction, in 5 different points equally spaced $(0.5 \mathrm{~m})$. The distance between the mechanical Source (S, i.e., the LWD) and the Receiver (R, i.e., the microphone) was called $d S R$. In each point, the LWD produced impulse loads and measured the elastic modulus, while the SHM system recorded the acoustic responses (acoustic signals) of the pavement sections under test to the impulse loads. It is important to note that the elastic modulus $(E)$ was considered in this study as a "traditional" parameter (affected by the problems discussed in section 2, e.g., interference with the traffic), and as a "control" parameter, i.e. to verify the consistency (validation) of the information derived from the signals recorded by the SHM system used in this experimental investigation. The signals gathered from the pavements, were analyzed in order to define their spectral contents, assumed as the acoustic signature of the pavements, and to extract one feature, i.e., the spectral centroid $\left(f_{c}\right)$, aiming at detecting structural variations based on acoustic signals (cf. [49]).

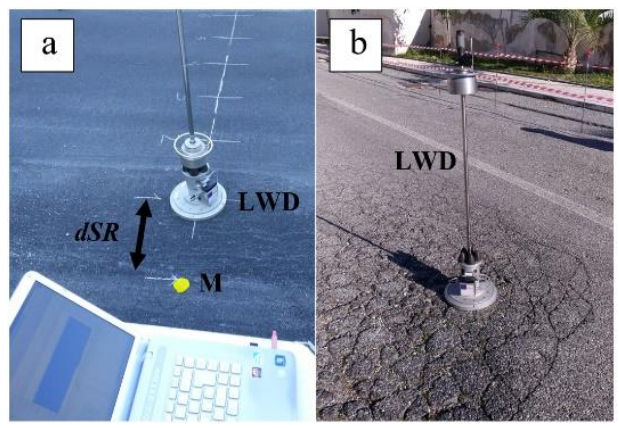

Figure 3. Determination of elastic moduli and acoustic responses of un-cracked, UC (a), and cracked, C (b), road pavement, at distances $d S R$ (Source: LWD; Receiver:

Microphone, M; yellow spot: modeling clay to fix M)

In this study, the spectral content was studied in terms of Power Spectral Density (PSD). The PSD of a signal of length $\mathrm{N}$ [samples], which was gathered using a sampling frequency (Fs), was calculated by first applying the Fast Fourier Transform (FFT) and subsequently the following expression [50]:

$P S D=2 \cdot \frac{|F F T|^{2}}{N \cdot F S}$

Based on the literature, the unit of measure of the PSD was expressed in decibel watt per $\mathrm{Hz}[\mathrm{dBW} / \mathrm{Hz}]$. Periodograms were obtained plotting the PSD as a function of the frequency. They were assumed as the acoustic signatures of the road pavements. From this domain, different features were extracted. Among all the possible ones the spectral centroid $\left(f_{c}\right)$ was taken into account in this study. This feature represents the "center of mass" of the Periodogram and can be determined using the following formula [51]:

$$
f_{c}=\frac{\sum_{n=0}^{N-1} p_{n} \cdot f_{n}}{\sum_{n=0}^{N-1} p_{n}}
$$

where $f_{c}$ is the spectral centroid [Hz], i.e., the abscissa of the "center of mass" of the periodogram (PSD vs. Frequency); $N$ is the sample length of the acoustic signal; $p_{n}$ represent the weights, i.e., the values on the y-axis; $f_{n}$ are the frequencies (xaxis of the Periodogram).

\section{RESULTS AND DISCUSSIONS}

The results of the experimental investigation are shown in Figure 4. Based on results, the averages of the elastic moduli and the spectral centroids for the two road sections under test were derived: i) for the UC section: $800 \mathrm{MPa}$ and $1000 \mathrm{~Hz}$; ii) for the $\mathrm{C}$ section: $200 \mathrm{MPa}$ and $700 \mathrm{~Hz}$.

Figure 4 illustrates how centroids $\left(f_{c}\right)$ and moduli vary as a function of the distance between source and receiver (x-axis). For a given distance, the UC section yield a spectral centroid and a modulus that are lower than the ones of the corresponding cracked, $\mathrm{C}$, section. Consequently, there is a correlation between the reduction of the stiffness (expressed by the elastic modulus) due to the presence of cracks and the variation of the spectral content (in terms of spectral centroid) of the acoustic responses of the pavement. This leads to the conclusion that the spectral centroid can be used as input parameter for the estimation of the pavement condition. For these reasons, the average values mentioned above (moduli and centroids) were used to build the curves that are shown in Figure 5.

Figure 5 shows three curves as a function of time and four couples of points: i) deterioration curve in terms of moduli (solid curve); ii) deterioration curve in terms of spectral centroids (dashed curve); iii) curve of management costs (dotted curve); iv) couple of points $\mathrm{P}$ (overlaid triangles, potential failure symptoms on solid and dashed curve); v) couple of points $\mathrm{F}$ (asterisks, functional failure on the solid and dashed condition curve); vi) couple of circles (solid and dashed, symptoms detected on the dashed curve); vii) couple of squares (solid and dashed, symptoms detected on the solid curve). The deterioration curves (solid line and dashed line in Figure 5) illustrate how the structural properties of the pavement decay over time. They were built using the four average values derived from the experimental investigation, based on the following hypotheses: i) the experimentally derived modulus $(E)$ and centroid $(f c)$ of the UC section refer to a 10 years old pavement and are close to the point $\mathrm{P}$ (fairto-good conditions, cf. Figure 1); ii) the experimentally derived $E$ and $f c$ of the $\mathrm{C}$ section refer to a pavement in poor to very poor conditions (cf. Figure 1 ), where $\mathrm{PC} \approx 20 \%$ in terms of modulus. They are close to the point $\mathrm{F}(\mathrm{PC} \approx 10 \%)$; iii) the expected life (i.e., the as-design design life) of the road pavement is about 25 years [52].

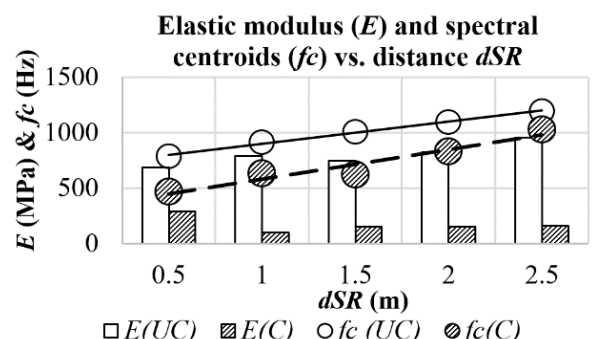

Figure 4. Moduli $(E)$ and centroids $\left(f_{c}\right)$ of the un-cracked (UC), and the cracked ( $\mathrm{C}$ section) pavements as a function of the distance Source-Receiver $(d S R)$ 


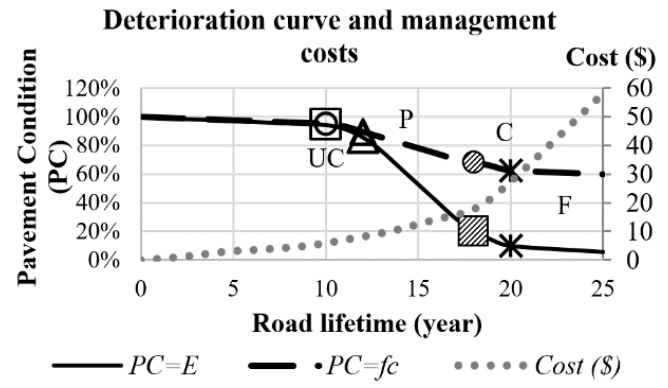

Figure 5. Deterioration curves built in terms of elastic moduli, $E$ (solid curve), and spectral centroid, $f_{c}$ (dashed curves); Management costs (dotted curve) built using the data in Table 1. Symbols. Triangles=points $P$ that refer to the Potential failure of the pavement; Asterisks $=$ points $\mathrm{F}$ that refer to the pavement Functional failure; Circles and Squares $=$ potential (solid) and functional (dashed) failures detected through the experimental investigation

By analyzing Figure 5, it is possible to state that the variation of the Pavement Conditions $(P C)$ of a road pavement can be expressed using deterioration curves built using "traditional" parameters, e.g., the elastic modulus $(E)$ of the road pavement $(P C=E)$, but also through "innovative" parameters, e.g., the spectral centroid $\left(f_{c}\right)$ extracted from the spectral content of the acoustic signature of the pavement ( $P C$ $=f_{c}$ ) gathered by using innovative SHM system. It should be noted that, the spectral centroid is just one out of the countless number of parameters that can be derived from the signals recorded using a SHM system. Based on these "innovative" parameters, specifically designed and weighted indices can be derived to express the pavement degradation. Hence, the proposed method has the potentialities to improve the current PMSs. In addition, the dotted curve in Figure 5 that refers to the maintenance and reconstruction costs was built using the information contained in Table 1. It shows that using an efficient monitoring system, i.e., able to identify automatically and in real-time the variation of the pavement condition, it is possible to save money and improve the overall sustainability of the management process. In more detail, maintenance costs $4 \$$ when potential failure has been early detected $(\mathrm{PC}=70 \%$ for $E$ ), but $18 \$$ are needed if the maintenance is carried out when functional failures are present and easily detectable (PC $=20 \%$ for $E$ ). In other words, the sooner the symptom is detected the higher the savings are. This result can be easily seen in terms of energy saving and carbon footprint reduction, because of the fact that money savings are mainly due to the energy saved reducing the maintenance interventions and, especially, avoiding the reconstruction of the road pavement.

\section{CONCLUSIONS}

A trade-off between the ever-growing request of Intelligent Transportation System (ITS) and the never-ending depletion of the available resources is needed. Several possible solutions that may be implemented in road infrastructures to reduce the current need of resources (in terms of energy, materials, money, time, and manpower) were presented and analyzed. The motivations behind the study are related to one of the possible solutions presented, i.e., PMSs optimization. The current PMSs aim at predicting and using deterioration curves of the road pavement, and for this reason they require input parameters. Unfortunately, "traditional" parameters are derived through methods that have usually need destructive, time-consuming, and expensive operations. Consequently, in this study, an innovative and sustainable method to improve the current PMSs was proposed. The prototypical validation of the method was carried out through an experimental investigation that was aimed at measuring two different parameters, one "traditional" and one "innovative", related to the structural health conditions of an un-cracked (UC section) and a cracked (C section) road pavement. A Light Weight Deflectometer (LWD) was used to measure the "traditional" parameter, i.e., the elastic modulus $(E)$, and as a source of vibration and sounds. The spectral content of the acoustic response of the pavements to the impulse loads was analyzed through periodograms (PSD vs. Frequency). Among the entire set of features that might be extracted from the periodograms, the spectral centroids $\left(f_{c}\right)$ were selected as "innovative" parameter in this study. The results of the experimental investigation show that the degradation of the pavement conditions (from the UC section to the $\mathrm{C}$ section) can be represented by the two parameters. In particular, a reduction of the road pavement elastic modulus (stiffness) corresponds to a reduction of the spectral centroid. Bearing in mind that, the spectral centroid is just one out of the countless number of parameters that can be derived from the signals recorded using a SHM system, and, under given conditions, the "innovative" parameters might replace the "traditional" ones. This last statement allows drawing the following conclusions: 1) "more sustainable" indices that represent the pavement conditions might be formalized and derived; 2) innovative deterioration curves might be drawn; 3) PMSs might be improved; 4) more efficient road management and rehabilitation processes could be carried out. The effect of the PMSs improvement can be seen in the short (i.e., timeliness in potential failure detection), middle (i.e., energy/money saving in maintenance and rehabilitation) and long term (i.e., carbon footprint reduction).

\section{REFERENCES}

[1] Bo P, Fan X, Wang X, Li W. (2017). Key steps of carbon emission and low-carbon measures in the construction of bituminous pavement. Int J Pav Res \& Tech 10(6): 476487. https://doi.org/10.1016/j.ijprt.2017.03.002

[2] Raab C, Camargo I, Partl MN. (2017). Ageing and performance of warm mix asphalt pavements. J Traf Transp Eng 4(4): 388-394. https://doi.org/10.1016/j.jtte.2017.07.002

[3] Du Y, Chen J, Han Z, Liu W. (2018). A review on solutions for improving rutting resistance of asphalt pavement and test methods. Constr \& Build Mat 168: 893-905. https://doi.org/10.1016/j.conbuildmat.2018.02.151

[4] Calvert SC, Taalea H, Sneldera M, Hoogendoorn SP. (2018). Improving traffic management through consideration of uncertainty and stochastics in traffic flow. Case St Transp Pol. 6(1): 81-93. https://doi.org/10.1016/j.cstp.2018.01.003

[5] Saikar A, Parulekar M, Badve A, Thakkar S, Deshmukh A. (2017). TrafficIntel, Smart Traffic Management for Smart Cities. Presented at ICEI17 Annual Meeting. https://doi.org/10.1109/ETIICT.2017.7977008

[6] Zheng C, Xu G, Xu K, Pan Z, Liang Q. (2015). An energy management approach of hybrid vehicles using traffic preview information for energy saving. En Conv 
$\&$ Manag. 105: $462-470$

https://doi.org/10.1016/j.enconman.2015.07.061

[7] Wilberforce T, El-Hassan Z, Khatib FN, Al Makky A, Baroutaji A, Carton JG, Olabi AG. (2017). Developments of electric cars and fuel cell hydrogen electric cars. Int J Hyd En. 42: 25695-25734. https://doi.org/10.1016/j.ijhydene.2017.07.054

[8] Su W, Chen X, Wang L. (2016). Analysis of energy saving and emission reduction of vehicles using light weight materials. En Proc. 88: 889-893. https://doi.org/10.1016/j.egypro.2016.06.106

[9] Moriarty P, Wang SJ. (2017). Could automated vehicles reduce transport energy? Presented at ICAE2017 Annual Meeting. https://doi.org/10.1016/j.egypro.2017.12.613

[10] Grauers A, Upendra K. (2016). Energy based method to analyse fuel saving potential of hybrid vehicles for different driving cycles. Presented at IFAC16 Annual Meeting. https://doi.org/10.1016/j.ifacol.2016.08.093

[11] Hu X, Zou Y, Yang Y. (2016). Greener plug-in hybrid electric vehicles incorporating renewable energy and rapid system optimization. Energy 111: 971-980. https://doi.org/10.1016/j.energy.2016.06.037

[12] Chen X, Wang H. (2018). Life cycle assessment of asphalt pavement recycling for greenhouse gas emission with temporal aspect. J Clean Prod 187: 148-157. https://doi.org/10.1016/j.jclepro.2018.03.207

[13] Balaguera A, Carvajal GI, Albertí J, Fullana-i-Palmerb P. (2018). Life cycle assessment of road construction alternative materials: A literature review. Res Cons \& Rec. 132: 37-48. https://doi.org/10.1016/j.resconrec.2018.01.003

[14] Wang T, Xiao F, Zhu X, Huang B, Wang J, Amirkhanian S. (2018). Energy consumption and environmental impact of rubberized asphalt pavement. J Clean Prod. 180: $139-158$ https://doi.org/10.1016/j.jclepro.2018.01.086

[15] Jamshidi A, Kurumisawa K, Nawa T, Jize M, White G. (2017). Performance of pavements incorporating industrial byproducts: A state-of-the-art study. J Clean Prod. 164: 367-388. https://doi.org/10.1016/j.jclepro.2017.06.223

[16] Appiah JK, Berko-Boateng VN, Tagbor TA. (2017). Use of waste plastic materials for road construction in Ghana. Case St in Constr Mat. 6: 1-7. https://doi.org/10.1016/j.cscm.2016.11.001

[17] Poulikakos LD, Papadaskalopouloub C, Hofko B, Gschösser F, Cannone Falchetto A, Bueno M, Arraigada M, Sousa J, Ruiz R, Petit C, Loizidou M, Part MN. (2017). Harvesting the unexplored potential of European waste materials for road construction. Res Cons \& Rec. 116:

$32-44$. https://doi.org/10.1016/j.resconrec.2016.09.008

[18] Praticò FG, Moro A, Noto S, Colicchio G. (2016). Threeyear investigation on hot and cold mixes with rubber. Presented at MAIREPAV16 Annual Meeting. https://doi.org/10.3850/978-981-11-0449-7-085-cd

[19] Wang C, Xue L, Xie W, You Z, Yang X. (2018). Laboratory investigation on chemical and rheological properties of bio asphalt binders incorporating waste cooking oil. Constr \& Build Mat. 167: 348-358. https://doi.org/10.1016/j.conbuildmat.2018.02.038

[20] Yang SH, Suciptan T. (2016). Rheological behavior of Japanese cedar-based biobinder as partial replacement for bituminous binder. Constr \& Build Mat. 114: 127-
133. https://doi.org/10.1016/j.conbuildmat.2016.03.100

[21] Xu X, Cao D, Yang H, He M. (2017). Application of piezoelectric transducer in energy harvesting in pavement. Int J Pav Res \& Tech. https://doi.org/10.1016/j.ijprt.2017.09.011

[22] Hasni H, Alavi AH, Chatti K, Lajnef N. (2017). A selfpowered surface sensing approach for detection of bottom-up cracking in asphalt concrete pavements: Theoretical/numerical modelling. Constr \& Build Mat. 144: 728-746. https://doi.org/10.1016/j.conbuildmat.2017.03.197

[23] Dezfooli AS, Nejad FM, Zakeri H, Kazemifard S. (2017). Solar pavement: A new emerging technology. Solar En. 149: 272-284. https://doi.org/10.1016/j.solener.2017.04.016

[24] Pan P, Wu S, Xiao Y, Liu G. (2015). A review on hydronic asphalt pavement for energy harvesting and snow melting. Renew \& Sust En Rev. 48: 624-634. https://doi.org/10.1016/j.rser.2015.04.029

[25] Xiang B, Cao X, Yuan Y, Sun L, Wu H., Haghighat F. (2018). A novel hybrid energy system combined with solar-road and soil regenerator: Dynamic model and operational performance. En Conv \& Manag. 156: 376387. https://doi.org/10.1016/j.enconman.2017.11.066

[26] Pop MD, Proștean O. (2018). A comparison between smart city approaches in road traffic management. Presented at SIM 2017 Annual Meeting. https://doi.org/10.1016/j.sbspro.2018.03.004

[27] Qin L, Dong L, Xu W, Zhang L, Yan Q, Chen X. (2017). A "vehicle in, light brightens; vehicle out, light darkens" energy-saving control system of highway tunnel lighting. Tunn \& Und Sp Tech. 66: 147-156. https://doi.org/10.1016/j.tust.2017.04.014

[28] He S, Liang B, Pan G, Wang F, Cui L. (2017). Influence of dynamic highway tunnel lighting environment on driving safety based on eye movement parameters of the driver. Tunn \& Und Sp Tech. 67: 52-60. https://doi.org/10.1016/j.tust.2017.04.020

[29] Yoomak S, Ngaopitakkul A. (2018). Optimisation of lighting quality and energy efficiency of LED luminaires in roadway lighting systems on different road surfaces. Sust Cit \& Soc. 38: 333-347. https://doi.org/10.1016/j.scs.2018.01.005

[30] Scarpati W, Guerra J. (2013). Investing in Pavement Management Can Improve Roads, Save Money. Munic Advoc. 27(2): 22-25.

[31] Morova N, Serin S, Terzi S, Saltan M. (2013). Prediction of the pavement serviceability ratio of rigid highway pavements by artificial neural networks. J Adv Tech Sc. 2(1): 12-25.

[32] Moubray J. (1997). Proactive maintenance 2: Predictive tasks. Reliability-Centered Maintenance, New York, USA: Ind. Press Inc. 7: 144-155.

[33] Vanderhawk Consulting LLC. (2011). Road Maintenance Philosophy: Best First vs. Worst First.

[34] Smadi O. (2004). Quantifying the benefits of pavement management. Presented at 6th International Conference on Managing Pavements. https://doi.org/10.1016/j.colsurfb.2006.05.011

[35] Hebel GC, Dorbit TG. Road Resurfacing Program. Harford County, USA. https://www.harfordcountymd.gov/615/RoadResurfacing-Program, accessed on Dec. 27, 2018.

[36] Lonbar MS, Nasrazadani SM, Shafaghat A. (2015). 
Investigation of aggregate and binder types effects on the micro surfacing rutting properties. Presented at ICICA15 Annual Meeting.

[37] Bruce MEC, Berg RR, Collin JG, Filz GM, Terashi M, Yang DS. (2013). Federal highway administration design manual: deep mixing for embankment and foundation support. Publication No. FHWA-HRT-13-046. Office of Transportation Management Federal Highway Administration, Washington DC, USA.

[38] National Center for Pavement Preservation. Pavement Deterioration Curve. Pavement preservation is cost effective.

http://images.slideplayer.com/35/10456260/slides/slide_ 34.jpg, accessed on Dec. 27, 2018.

[39] Springfield Department of Public Works. (2009). Pavement Management. City of Springfield, Massachusetts, USA. https://www.springfieldma.gov/dpw/index.php?id=121, accessed on Dec. 27, 2018.

[40] Yu B, Xingyu G, Fujian N, Rui G. (2015). Multiobjective optimization for asphalt pavement maintenance plans at project level: Integrating performance, cost and environment. Transp Res Part D. 41: 64-74. https://doi.org/10.1016/j.trd.2015.09.016

[41] Praticò FG, Vaiana R, Giunta M. (2013). Pavement Sustainability: Permeable Wearing Courses by Recycling Porous European Mixes. J Arch Eng. 19 (3): 186-192. https://doi.org/10.1061/(ASCE)AE.19435568.0000127

[42] Varela-González M, Solla M, Martínez-Sánchez J, Arias P. (2014). A semi-automatic processing and visualisation tool for ground-penetrating radar pavement thickness data. Aut in Constr. 45: 42-49. https://doi.org/10.1016/j.autcon.2014.05.004

[43] Svenson K. (2013). Estimated lifetimes of road pavement in Sweden using time-to-event analysis. Dalarna University, Sweden.
[44] Lin S, Ashlock JC, Williams RC. (2016). Nondestructive quality assessment of asphalt pavements based on dynamic modulus. Constr \& Build Mat. 112: 836-847. https://doi.org/10.1016/j.conbuildmat.2016.02.189

[45] Nazarko J, Radziszewski P, Dębkowska K, Ejdys J, Gudanowska A, Halicka K, Kilon J, Kononiuka A, Kowalski KJ, Król JB, Nazarko L, Sarnowski M, Vilutienè T. (2015). Foresight study of road pavement technologies. Proc. Eng. 122: 129-136. https://doi.org/10.1016/j.proeng.2015.10.016

[46] Shi Y, Meng X, Zhao J, Hu X, Liu B, Wang H. (2010). Benchmarking cloud-based data management systems. Presented at Cloud DB10, Toronto, CA, 2010. https://doi.org/10.1145/1871929.1871938

[47] Fedele R, Praticò FG, Carotenuto R, Della Corte FG. (2017). Instrumented infrastructures for damage detection and management. Presented at MT-ITS17. https://doi.org/10.1109/MTITS.2017.8005729

[48] ASTM E2583-07(2015), Standard Test Method for Measuring Deflections with a Light Weight Deflectometer (LWD), ASTM International, West Conshohocken, PA, 2015, www.astm.org. https://doi.org/10.1520/E2583-07R15

[49] Fedele R, Della Corte FG, Carotenuto R, Praticò FG. (2017). Sensing road pavement health status through acoustic signals analysis. Presented at PRIME 17 Annual Meeting. https://doi.org/10.1109/PRIME.2017.7974133

[50] Bendat JS, Piersol AG. (2010). Random data analysis and measurement procedures. Measurement Science and Technology 11(12), 4th ed.

[51] Schubert E, Wolfe J. (2006). Does timbral brightness scale with frequency and spectral centroid? Acta Ac Un Ac. 92: 820-825.

[52] Postorino MN, Praticò FG. (2012). An application of the multi-criteria decision making analysis to a regional Multi-airport system. Res in Transp Bus \& Manag. 4: 44-52. https://doi.org/10.1016/j.rtbm.2012.06.015 